\title{
GCU
}

Glasgow Caledonian

University

University for the Common Good

\section{A novel on-line cable PD localisation method based on cable transfer function and detected PD pulse rise-time}

Sheng, Bojie; Zhou, Chengke; Hepburn, Donald; Dong, Xiang ; Peers, Graham; Wenjun, Zhou; Tang, Zeyang

Published in:

IEEE Transactions on Dielectrics and Electrical Insulation

DOI:

10.1109/TDEI.2015.004398

Publication date:

2015

Document Version

Author accepted manuscript

Link to publication in ResearchOnline

Citation for published version (Harvard):

Sheng, B, Zhou, C, Hepburn, D, Dong, X, Peers, G, Wenjun, Z \& Tang, Z 2015, 'A novel on-line cable PD

localisation method based on cable transfer function and detected PD pulse rise-time', IEEE Transactions on Dielectrics and Electrical Insulation, vol. 22, no. 4, pp. 2087-2096. https://doi.org/10.1109/TDEl.2015.004398

\section{General rights}

Copyright and moral rights for the publications made accessible in the public portal are retained by the authors and/or other copyright owners and it is a condition of accessing publications that users recognise and abide by the legal requirements associated with these rights.

Take down policy

If you believe that this document breaches copyright please view our takedown policy at https://edshare.gcu.ac.uk/id/eprint/5179 for details

of how to contact us. 


\title{
A Novel On-line Cable PD Localisation Method Based on Cable Transfer Function and Detected PD Pulse Rise-time
}

\author{
Bojie Sheng, Chengke Zhou, Donald M. Hepburn, Xiang Dong \\ Glasgow Caledonian University \\ School of Engineering and Built Environment \\ Glasgow, G4 0BA, UK \\ Graham Peers \\ EDF Energy \\ East Kilbride, G74 5PG, UK \\ Wenjun Zhou and Zeyang Tang \\ Wuhan University \\ School of Electrical Engineering \\ Wuhan, 430072, China
}

\begin{abstract}
This paper presents a novel Partial Discharge (PD) localisation method, based on PD pulse Rise-Time and Transfer Function (RTTF), for use in on-line cable PD monitoring systems. This is based on the change in rise time as a function of cable length along which a PD pulse has propagated. A comparison with four other well-known location techniques, i.e. Time-Domain Reflectometry (TDR), Phase difference, Arrival Time Analysis (ATA) and Amplitude-Frequency (AF) mapping has been made and presented. Analysis shows that the TDR and Phase difference methods, although requiring a single measurement point, are only applicable to short length cable systems as both incident pulse and reflected pulse should be observable when it reaches the detection point. On the other hand, the ATA and AF mapping, which can be applied to longer cable systems, need to install detectors at multiple points and detect synchronously. In comparison, PD localisation by the proposed RTTF method, which requires detection of the incident pulse at only one measurement point, can be used to localise a PD source which is further away from the PD detection point than other methods and can be used in on-line PD monitoring systems. As on-line PD monitoring sensors commonly comprise of a high frequency current transformer (HFCT) and a high-pass filter, the rise time of detected PD pulses depends on the attenuation of the cable, the HFCT used and the filter applied. Simulations of pulse propagation in a cable and PD monitoring system are performed, based on analyses in the frequency domain using the concept of transfer functions. Results of RTTF from the simulations have been verified by laboratory experiments and on-site PD measurements, which provide evidence that the RTTF method is a very valuable and useful PD localisation technique.

Index Terms - Cable, partial discharge, on-line monitoring, rise time, transfer function, localisation.
\end{abstract}

\section{INTRODUCTION}

PD measurement is widely recognised as a useful tool for assessing the quality of the insulation system of $\mathrm{HV}$ and MV power cables. It should, however, be noted that, although on- line PD detection can warn of existence of PD activities, a technical breakthrough is still required for on-line location of the site of origin of serious insulation problems before a breakdown, so that timely actions can be taken on defects in insulation, cables joints or terminations [1].

A major challenge in accurately locating the source of PD activities in power cables is that PD pulses suffer from significant attenuation and dispersion as they travel from their site of origin 
to the cable terminal or cable joint where a PD monitoring system is connected. This attenuation and dispersion results in detected PD signals possessing different waveforms from the original PD pulse. Identifying and establishing correlation between the PD pulse at the site of origin and that at the detection point(s) for localisation of the signal source becomes crucial [2].

Four on-line PD localisation methods have been extensively discussed in literatures and are outlined as follows. Firstly, TimeDomain Reflectometry (TDR) [3], although TDR requires only a single measurement point at one of the terminations or joints, and it is convenient, fast and cheap, it can only be carried out on short cables as the method relies on detection of the incident and reflected pulses. The reflected wave usually suffers too much attenuation and cannot be detected properly in a long cable system, this is especially so when strong noise exists. Secondly, the Phase difference method, this technique estimates the location of the PD from the phase difference of each Fourier frequency between the incident and reflected signals [4]. It has the advantage that it is not necessary to estimate the arrival time interval between the incident and reflected pulses; however, the average error is unacceptable when the PD source is close to cable ends and it suffers from the same attenuation of reflected signal problem as the TDR method. Thirdly, Arrival Times Analysis (ATA) method derives the location by means of simultaneous detection and sampling at different locations [5]. Consequently this method requires laying fiber optic cables from the sensors installed at different points along the cable route to a single acquisition system, it is time-consuming and can be expensive as it involves considerable human and technological resources. Lastly, Amplitude-Frequency (AF) mapping method is based on the comparison of the time and frequency domain characteristics of PD pulses detected from several measurement locations [6]. It is applicable to long cable circuits, but it can only be regarded as a pre-screening technique as it often yields ambiguous location results, especially when a circuit is directly buried where cable accessories are not accessible.

In the present paper, a new technique for PD localization termed Rise-Time Transfer Function (RTTF) is developed for use in on-line cable PD monitoring. It only needs to detect and analyse the incident PD pulse to locate the PD source. The method relies on the fact that the rise time of a detected PD pulse is a function of cable length along which a PD pulse has propagated before reaching the measurement point (cable joint or termination). Therefore, it can be both convenient to apply and is suitable for long cable circuit, as it does not need to have information from the reflected pulse.

\section{PD CHARACTERISTICS OF PULSE PROPAGATION ALONG POWER CABLE AND MONITORING SYSTEM}

\subsection{MATHEMATICAL EXPRESSION OF A PD PULSE}

According to [6], a PD pulse can be assumed as a double exponential wave defined by the equation:

$$
V(t)=V_{0}\left(-\exp \left(-t / \tau_{1}\right)+\exp \left(-t / \tau_{2}\right)\right)
$$

Where: $\tau_{1}, \tau_{2}=$ time constants $(\mathrm{s})$

$$
\mathrm{V}_{0}=\text { amplitude constant }(\mathrm{V})
$$

The shape of a pulse can be defined by rise time $\mathrm{T}_{\mathrm{r}}$ (rise from $10 \%$ to $90 \%$ of the peak) and pulse width $\mathrm{T}_{\mathrm{FWHM}}$ (full width at half maximum), which is shown in Figure 1.

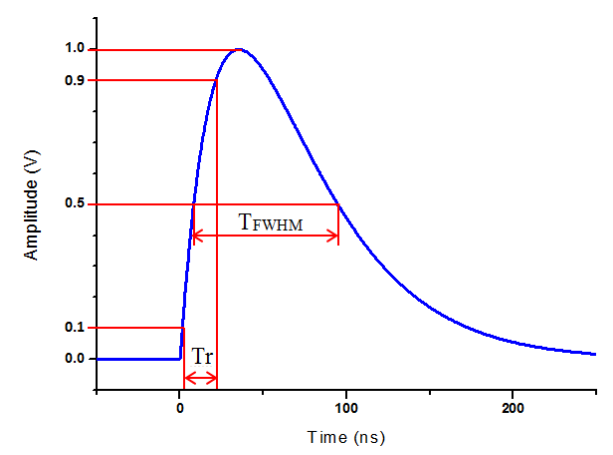

Figure 1: Illustration of $\operatorname{Tr}$ and $\mathrm{T}_{\mathrm{FWHM}}$ of a PD pulse.

\subsection{THEORETICAL BACKGROUND}

As on-line PD monitoring sensors commonly comprise of a high frequency current transformer (HFCT) and a high-pass filter (HPF) [7], the characteristics of detected PD pulses depend on the attenuation of the cable, the HFCT used and the HPF applied. Therefore the characteristics of pulse propagation in a cable and PD monitoring system are based on analyses in the frequency domain using the concept of transfer functions.

\subsubsection{CABLE TRANSFER FUNCTION}

The power cable, behaving as a transmission line to a travelling wave or signal can be described by an equivalent circuit with distributed parameters per unit length, resistance $\mathrm{R}(\Omega / \mathrm{m})$, inductance $\mathrm{L}(\mathrm{H} / \mathrm{m})$, conductance $\mathrm{G}(\mathrm{S} / \mathrm{m})$, and capacitance $\mathrm{C}$ $(\mathrm{F} / \mathrm{m})$, which is shown in Figure 2 [8].

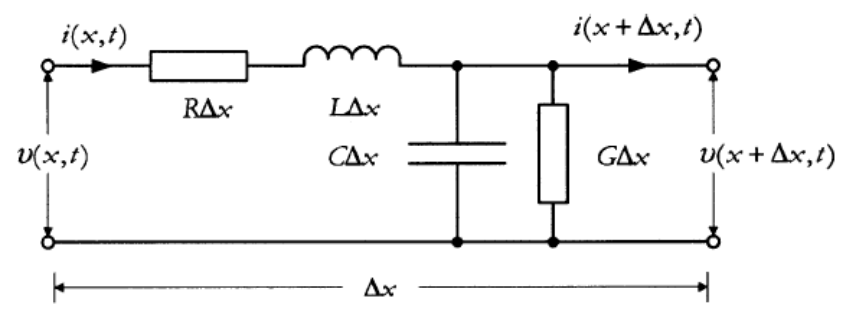

Figure 2. Equivalent circuit representation of a transmission line element of length $\Delta \mathrm{x}$

Inductive and capacitive circuit parameters are frequency dependent, where frequency is given by $f(\mathrm{~Hz})$. The line is described by its propagation constant $\gamma$ with attenuation constant $\alpha(\mathrm{dB} / \mathrm{m})$ as real and phase constant $\beta(\mathrm{rad} / \mathrm{m})$ as the imaginary part. The following relation holds:

$\gamma(\omega)=\alpha(\omega)+j \beta(\omega)=\sqrt{(R+j \omega L)(G+j \omega C)}$

Where: $\omega=2 \pi f$ is angular velocity ( $\mathrm{rad} / \mathrm{sec})$

As different frequencies of a pulse travel along a cable, they suffer different degrees of attenuation and dispersion. Attenuation $\alpha$ is due to losses in the solid dielectric and propagation through the resistance of the conductor, sheath and semi-conducting layers. Normally, attenuation severity increases with frequency. Dispersion is a phenomenon whereby different frequency signals travel along a cable at different speeds, which results in 
frequency-dependent phase shifts. Therefore, it can be said that attenuation and dispersion will decrease the amplitude and increase the width of the pulse, hence changing the rise time, as the pulse propagates along a cable [6].

The propagation constant of a wave travelling along a transmission line of segment length $l$ is the complex ratio between the voltages of output (transmitted) pulse $\mathrm{V}_{\text {out }}$ and the input (incident) pulse $\mathrm{V}_{\text {in }}$ of the line segment. If a length of cable is considered as a linear system, this ratio represents the cable Transfer Function $\mathrm{H}_{\text {cable }}(\omega)$ as:

$H_{\text {cable }}(\omega)=\frac{\mathrm{V}_{\text {out }}}{\mathrm{V}_{\text {in }}}=e^{-r(\omega) 2 l}=e^{-(\alpha(\omega)+j \beta(\omega)) 2 l}$

Although the input pulse and output pulse cannot be measured directly due to existence of mismatched impedance between the samples and instrumentation, a calibration procedure has been developed to obtain $\mathrm{H}_{\text {cable }}(\omega)$ [9]. Set-up of the procedure can be discussed using Figure 3: initially line 2 is short-circuited and the measured signal from this configuration is $\mathrm{V}_{-3}$ short, thereafter the device under test (DUT) is connected to line 2 and the data collected. From this the transfer function of the system can be obtained from:

$$
H_{\text {cable }}(\omega)=e^{-r(\omega) 2 l}=\frac{V_{-3} V_{-3}^{\text {short }}}{\left(V_{-3}^{m}\right)^{2}-\left(V_{-3}^{\text {short }}\right)^{2}}
$$

Where $\mathrm{V}_{-3}$ is the DUT response, $\mathrm{V}_{-3}{ }^{\text {short }}$ is the measured signal reflected at the short-circuited end of coaxial line 2 and $\mathrm{V}_{-3}{ }^{\mathrm{m}}$ is the mismatch reflection.

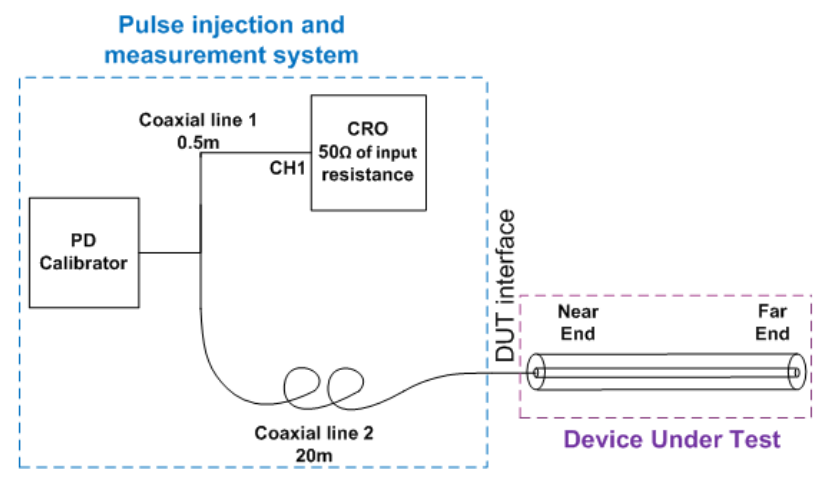

Figure 3. Schematic drawing of a calibration procedure setup

The attenuation and phase constant can be deduced from equation (4) as

$$
\begin{aligned}
& \alpha(\omega)=-\frac{1}{2 l} \ln \left|H_{\text {cable }}(\omega)\right| \\
& \beta(\omega)=-\frac{1}{2 l} \angle H_{\text {cable }}(\omega)
\end{aligned}
$$

Following the calibration procedure, an experiment was carried out by injecting a calibration pulse shown in Figure 4 into a 38.8 m $11 \mathrm{kV}$ single core Ethylene-Propylene-Rubber (EPR) insulated cable specimen, which consists of copper conductor, EPR polymeric insulation, copper tape concentric screen and PVC sheath, to obtain the transfer function of the EPR cable. The measured attenuation and phase constant are given in Figure 5.

Results shown in Figure 5 indicate that the cable behaves like a transmission line up to $80 \mathrm{MHz}$, beyond this the characteristics becomes complicated and the cable cannot be represented using the transfer function as described in the paper.

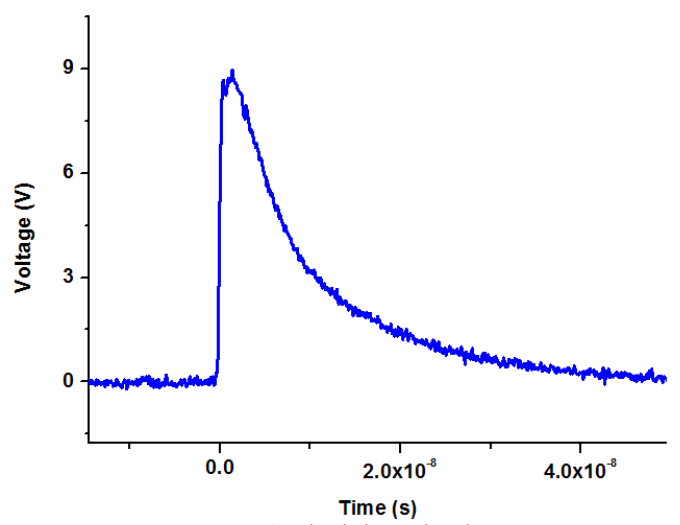

Figure 4. The injected pulse

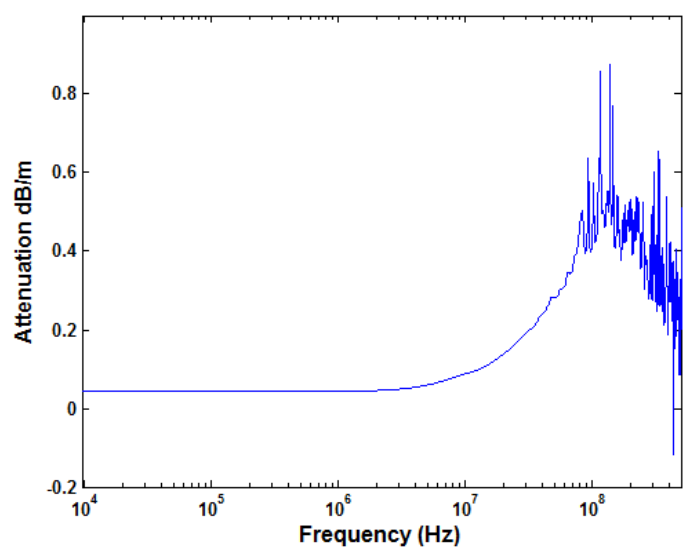

(a) Attenuation constant

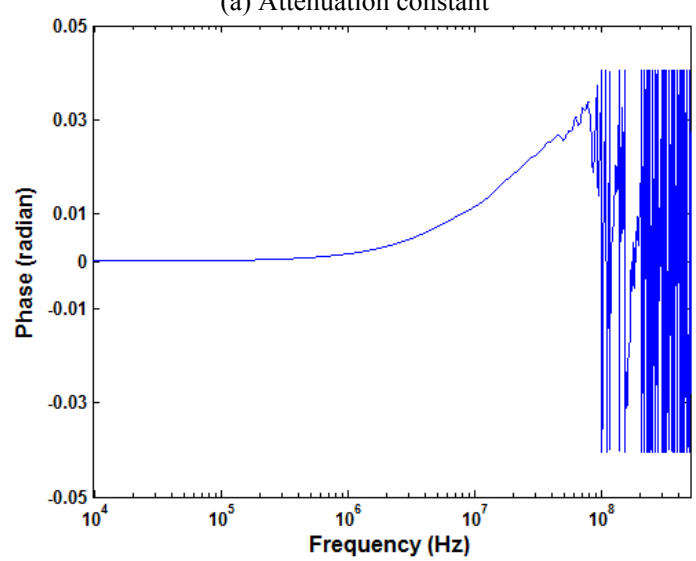

(b) Phase constant

Figure 5. Measured results of attenuation and phase constant of an $11 \mathrm{kV}$ EPR insulated cable

\subsubsection{HFCT TRANSFER FUNCTION}

A high frequency current transformer (HFCT) is designed specifically for picking up partial discharge current signals. It has a split ferrite core to allow retrospective fitting to earth bond lead 
without the need for disconnection of the cable under test. A typical HFCT for on-site PD detection has a frequency range of $50 \mathrm{kHz}$ to $20 \mathrm{MHz}$ with the transfer function of the HFCT $\left(\mathrm{H}_{\mathrm{HFCT}}\right.$ $(\omega)$ ), developed from equation (7), being shown in Figure 6. Frequency and phase responses are shown in Figures $6 \mathrm{a}$ and $6 \mathrm{~b}$ respectively.

$$
H_{H F C T}(\omega)=\frac{\mathrm{V}_{\text {out }}}{l_{\text {in }}}
$$

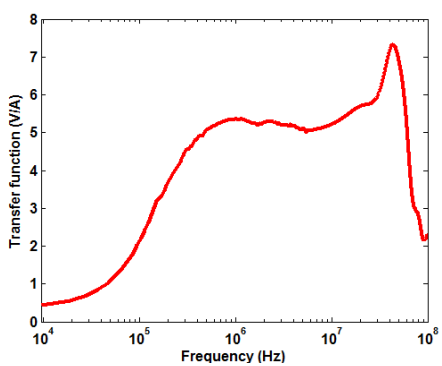

(a) Frequency response

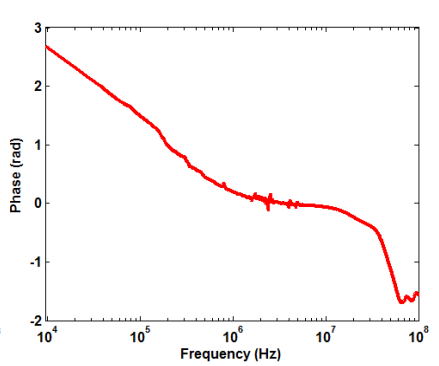

(b) Phase response
Figure 6. Experimental data of transfer function of HFCT.

\subsubsection{FILTER TRANSFER FUNCTION}

A first-order resistance-capacitance (RC) high-pass filter (HPF) is usually used as a PD filter in on-line monitoring systems. This is a filter that is designed to pass high-frequency signals but attenuates (reduces the amplitude of) signals with frequencies lower than the cutoff frequency, as PD signals contain high frequencies they are able to pass through the filter, while mains frequencies and lower harmonics are blocked. The value of resistance $\mathrm{R}$ and capacitance $\mathrm{C}$ are $50 \Omega$ and $0.01 \mu \mathrm{F}$ respectively, giving a cut-off frequency of $318 \mathrm{kHz}$. The transfer function of the HPF is given in Equation (8) below:

$H_{H P F}(\omega)=\frac{V_{\text {out }}}{V_{\text {in }}}=\frac{1}{1-\mathrm{j}(1 / \omega R C)}$

\subsection{PULSE PROPAGATION IN CABLE AND MONITORING SYSTEM}

A simulation of pulse propagation in an $11 \mathrm{kV}$ EPR cable which was described in Section 2.2.1 and the monitoring system has been made. The methodology for carrying out the simulation can be summarized briefly as follows: Firstly, a double exponential pulse is assumed as an original pulse, or input pulse, $\mathrm{V}_{\text {in }}(\mathrm{t})$ which has been generated at one end of the cable with a length of L. Secondly, the incident pulse is converted into the frequency domain $\mathrm{S}_{\text {in }}(\omega)$ via Fast Fourier Transform (FFT). Thirdly, the output pulse, or detected pulse, from PD monitoring system installed at the other end of the cable in frequency domain $\mathrm{S}_{\text {out }}(\omega)$ is determined by multiplying $\mathrm{S}_{\text {in }}(\omega)$ and transfer function $\mathrm{H}_{\text {pro }}(\omega \mathrm{L})$ which is defined in equation (9). Finally, the output pulse in time domain $\mathrm{V}_{\text {out }}(\mathrm{t})$ can be obtained by Inverse FFT, then the shape parameters of the output pulse: $T_{r}$ and $T_{F W H M}$ can be extracted.

$$
H_{\text {pro }}(\omega L)=H_{\text {cable }}(\omega L) * H_{H F C T}(\omega) * H_{H P F}(\omega)
$$

In the simulation, the assumed original pulse has $1 \mathrm{~ns}$ rise time and 3 ns $\mathrm{T}_{\mathrm{FWHM}}$ while the cable length $\mathrm{L}$ varies from 0 to $3000 \mathrm{~m}$. Simulation results given in Figure 7 demonstrate that the rise time and the pulse width of the output pulses increase monotonically with length of cable over which the pulse has propagated. Furthermore, this result suggests that for a known original pulse, a certain rise time of detected pulse has unique cable length which the pulse has propagated. As a consequence, when a pulse is detected at a measurement point, the original pulse at its site of origin can be derived, assuming that the rise time of the original pulse is obtainable.

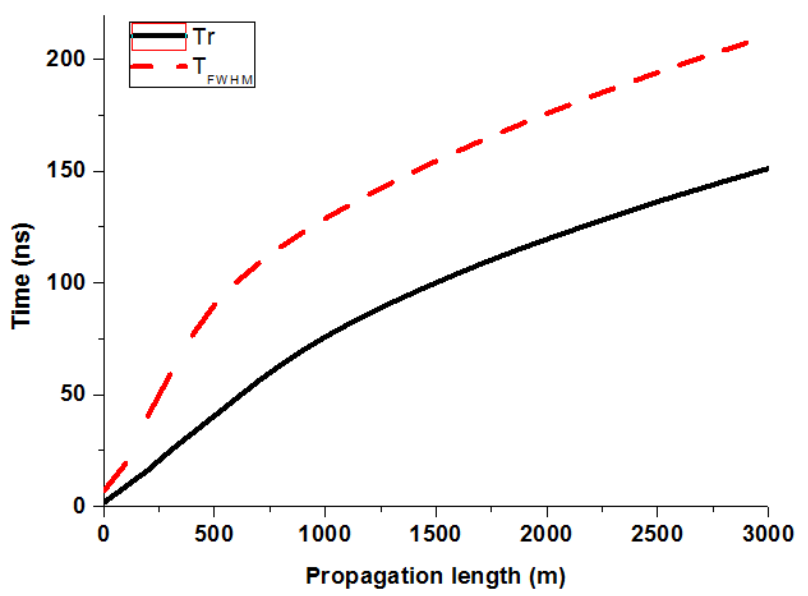

Figure 7. Simulation results of pulse propagation in cables with different length: black line is rise time value while red line is pulse width value.

\section{PROPOSED LOCALISATION ALGORITHM AND SIMULATION}

\subsection{PROPOSED LOCALISATION TECHNIQUE}

The proposed PD localization method, termed Rise-Time Transfer Function (RTTF), has been developed under two prerequisites. One is the establishment of a knowledge base of the correlation of rise time and pulse propagation distance for a cable. This needs to be carried out for each different cable, as detailed in Section 3.2. The other is assuming that all original PD pulses have a rise time of $1 \mathrm{~ns}$, which is based on the experimental findings that the variation in rise time of original PD pulses at their defect sites is between $0.2 \mathrm{~ns}$ and $2.3 \mathrm{~ns}$ while rise time of original PD pulses mainly is $1 \mathrm{~ns}[10,11,12]$. Moreover, even if the rise time of any PD pulse at its site of origin differs from the assumed $1 \mathrm{~ns}$, the error of RTTF method in localization result is insignificant, which is demonstrated in Section 3.2. The RTTF technique used for on-line PD localization is elaborated in Section 3.3.

\subsection{ESTABLISHMENT OF A KNOWLEDGE BASE OF CORRELATION OF RISE TIME VS DISTANCE}

Establishment of a knowledge base of a function of rise time vs pulse propagation distance takes two steps, as shown in Figure 8. The first is to carry out experiments to obtain the transfer functions of the cable under analysis, the 
HFCT and the HPF being used. The second is to use the transfer functions to produce the knowledge base by simulation of pulse propagation in the cable and the PD monitoring system.

As different types of power cables have different transfer functions, the characteristic of rise time of a PD pulse after propagation of a certain distance in a cable is different. Experiments on samples of different types of power cables should be carried out under laboratory conditions to obtain the cable transfer function $\mathrm{H}_{\text {cable }}(\omega)$, and the transfer functions of HFCT and HPF being used should also be specifically obtained, as shown in Section 2.2. The resultant transfer function $\mathrm{H}_{\text {pro }}(\omega \mathrm{L})$ of pulse propagation in different types of cables and monitoring system is defined by equation (9).

After the experiments, a simulation using the transfer function $\mathrm{H}_{\text {pro }}(\omega \mathrm{L})$ and an assumed original pulse with $1 \mathrm{~ns}$ rise time and $3 \mathrm{~ns} \mathrm{~T}_{\mathrm{FWHM}}$ is performed to simulate the pulse propagation in cable and monitoring system. The simulation method is the same as that presented in Section 2.3 , and the desired result is a function correlating rise time of detected pulse and pulse propagation distance.

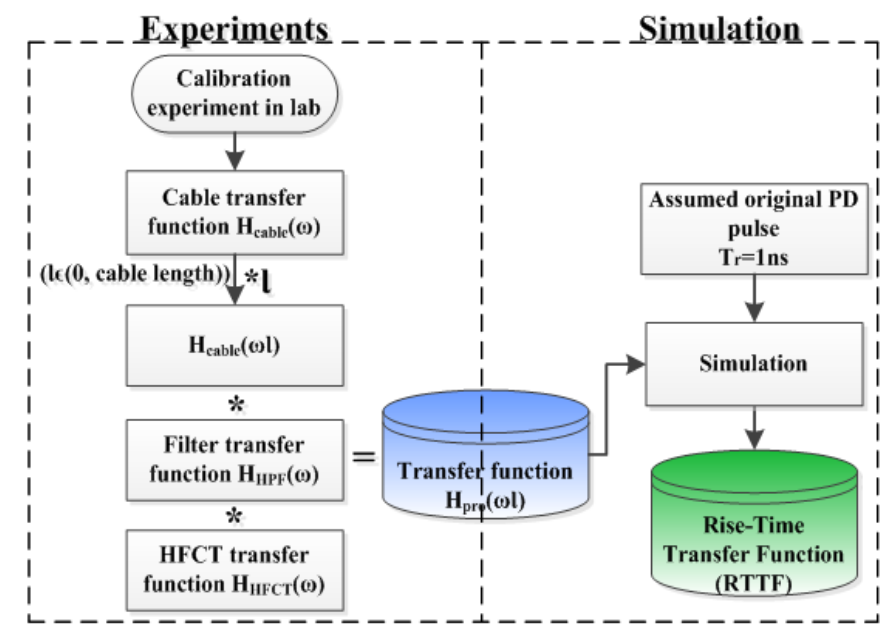

Figure 8. Establishment of a knowledge base of correlation of rise time and distance.

As this simulation is based on the analysis in frequency domain, the simulation result depends on the assumed original pulse shape. Therefore, the simulation result, RTTF, for a defined cable is affected by the shape of the original pulse.

According to references [10-12], the variation in rise time of original PD pulses at source is between $0.2 \mathrm{~ns}$ and $2.3 \mathrm{~ns}$ and pulse width is between $0.8 \mathrm{~ns}$ and $7.9 \mathrm{~ns}$. Different original pulses are therefore assumed for simulations of pulse propagation in cable and monitoring system to investigate the error of RTTF comparing with that in Section 3.2 .

Three pulses with different shapes but possessing the same magnitude, as shown in Figure 9a, are assumed as different original pulses for the simulation. The rise time/pulse width of the three pulses is $1 / 3 \mathrm{~ns}, 1.5 / 4.5 \mathrm{~ns}$ and $2 / 6 \mathrm{~ns}$ respectively. The transfer function of an $11 \mathrm{kV}$ EPR cable as described in Section 2.2.1 is used in simulations and simulation results are given in Figure $9 b$.

As shown in Figure 9, the RTTFs differ for different original pulse shapes. The difference between $1 / 3$ ns pulse and the other pulses is distinguishable below $100 \mathrm{~m}$ while it is inconspicuous beyond $100 \mathrm{~m}$, but the variation is negligible.

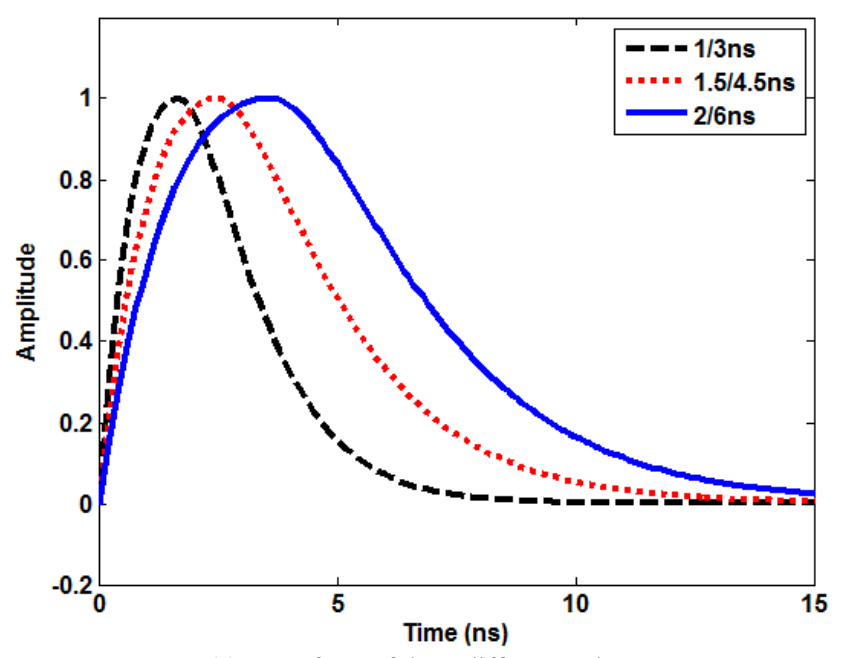

(a) Waveform of three different pulses

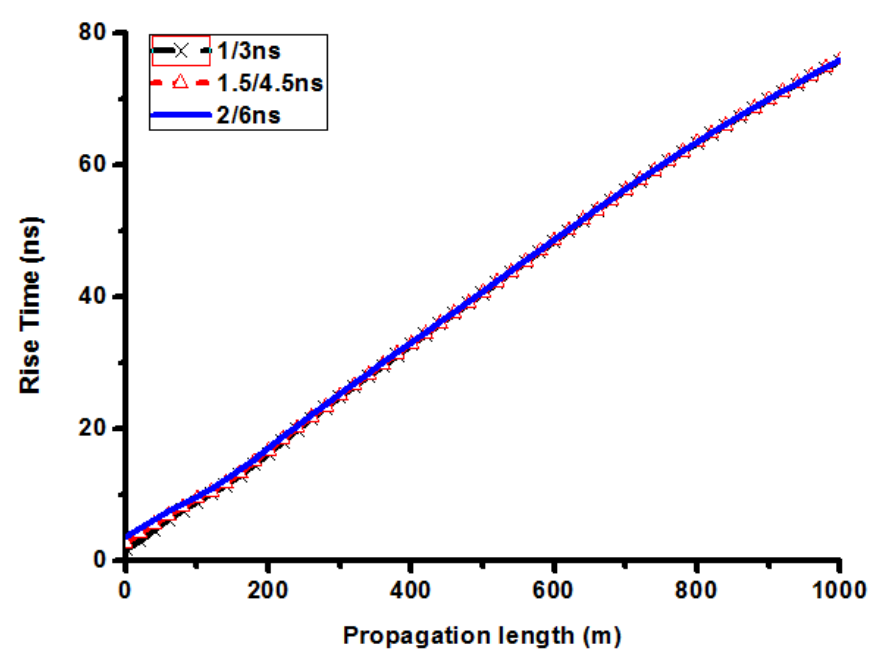

(b) Results of rise time as a function of propagation distance

Figure 9: Simulation of rise time functions with different incident pulses.

\subsection{PD LOCALISATION IN ON-LINE PD MONITORING}

With the establishment of the knowledge base of correlation of rise time and distance, the RTTF technique for PD localization in on-line PD monitoring can be summarized briefly as follows:

1) An on-line $\mathrm{PD}$ monitoring system installed at one measurement point (cable joint or termination) of a cable circuit is used for data acquisition.

2) Denoising and pattern recognition techniques are applied to remove noise and identify individual PD pulses [13-15].

3) Rise times of individual PD pulses are extracted.

4) Comparing the rise times of detected pulses with the RTTF of the defined cable in the knowledge base to obtain the pulse propagation distance to locate the PD source. 


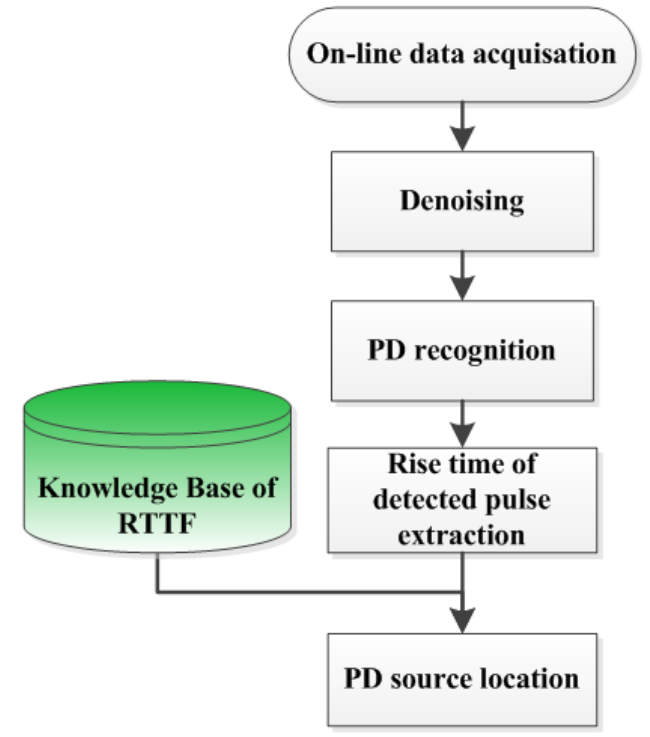

Figure 10. Schematic diagram of PD localization in on-line PD monitoring.

\section{EXPERIMENTAL INVESTIGATION AND PRACTICAL APPLICATION}

\subsection{EXPERIMENTAL VERIFICATION FOR PULSE PROPAGATION IN A CABLE}

Laboratory experiments were carried out on a $38.8 \mathrm{~m} 11 \mathrm{kV}$ EPR insulated single core cable to verify the simulation method for pulse propagation only, in a cable, without propagation through the monitoring system. An oscilloscope with a sampling rate of $10 \mathrm{GS} / \mathrm{s}$, a vertical resolution of 8 bits, and a bandwidth of $3 \mathrm{GHz}$ has been used for data acquisition. A PD calibrator which can generate a pulse with 1 ns rise time was used in the experiment. As it is difficult to capture the input pulse and output pulse simultaneously, due to impedance mismatch between the cable and the measurement system, the experiments had to be specifically designed to ignore the effect of the pulse reflection as a pulse entered the cable sample. Experimental set-ups are shown in Figure 11. In both set-ups, the PD calibrator was connected to two lengths of coaxial cable by a T-connection. In set-up $1,0.5 \mathrm{~m}$ long coaxial cable 1 is connected to the PD calibrator while the other end connects to channel 1 of the oscilloscope by a $10 \mathrm{~dB}$ attenuator, $20 \mathrm{~m}$ long coaxial cable 2 is connected to channel 2 using a $10 \mathrm{~dB}$ attenuator. In set-up two, cable 1 connects between the PD calibrator and the oscilloscope as previously, cable 2 connects to one end of the EPR cable under test. The other end of the cable connects to channel 2 of the scope using $0.5 \mathrm{~m}$ long coaxial cable 3 .

The experimental results are depicted in Figure 12, where:

$\mathrm{V}_{11}$ - pulse detected in channel 2 in set-up one.

$\mathrm{V}_{21}$ - first pulse detected in channel 2 in set-up two.

$\mathrm{V}_{23}$ - third pulse detected in channel 2 in set-up two.

$\mathrm{V}_{24}$ - fourth pulse detected in channel 2 in set-up two.

In Figure 12a the first pulse is that detected at channel $1 . \mathrm{V}_{11}$ is the pulse detected at channel 2 and, thus, the pulse injected into the end of the power cable section in the second set-up.

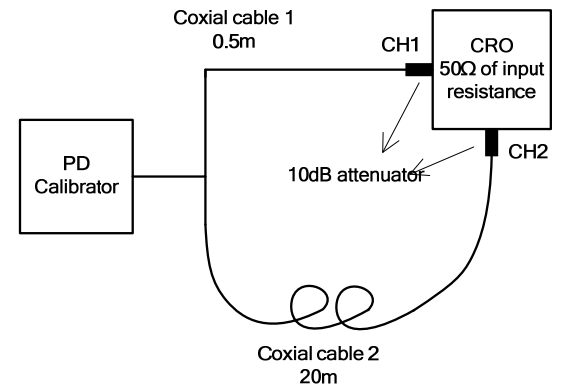

(a) Set-up one

Pulse injection and measurement system

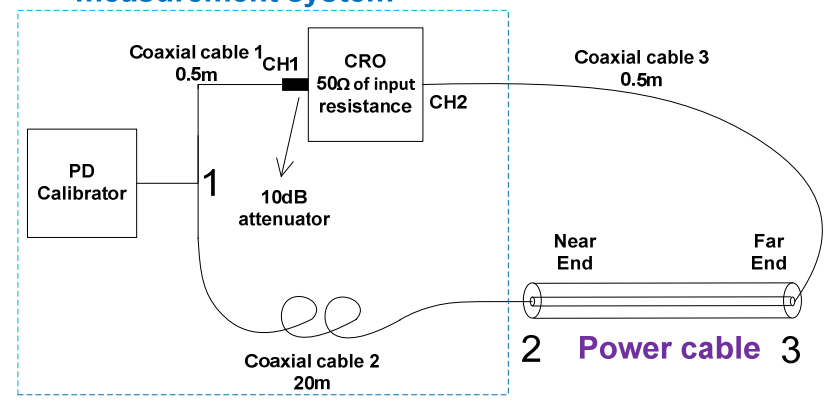

(b) Set-up two

Figure 11. Experiment set-ups in laboratory.

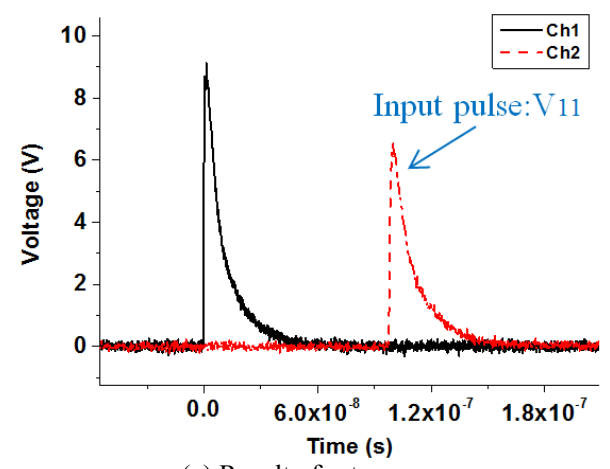

(a) Result of set-up one

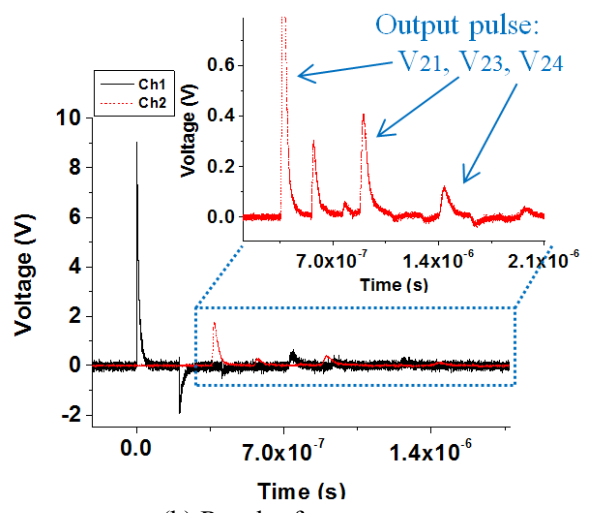

(b) Result of set-up two

Figure 12. Experimental results.

The shape of the incident pulse injected into the cable in set-up two can be considered the same as that of $\mathrm{V}_{11}$. At the start of the cable, due to impedance mismatch, part of the signal will be reflected but the pulse shape will be maintained. The output pulse detected at channel 2 will be proportional to the signal at the cable end but the magnitude will be reduced. 
The shape, not the magnitude, of $\mathrm{V}_{21}, \mathrm{~V}_{23}$ and $\mathrm{V}_{24}$ are considered in the output pulses from the cable, attenuation of coaxial cable 3 is ignored. The propagation lengths of $V_{21}, V_{23}$ and $\mathrm{V}_{24}$ are, respectively, once, three times and five times the length of the cable under test.

Simulations have been carried out for the pulse $V_{11}$ to travel the whole cable length, three times and five times of the length of the EPR cable individually. A comparison of normalized output pulses resulting from simulation and those from experimental results are given in Figure 13. It can be observed that simulation results for pulse propagation in a cable are in good agreement with experimental results for all three cable lengths, i.e. $38.8 \mathrm{~m}, 116.4 \mathrm{~m}$ and $194 \mathrm{~m}$. Due to the limitation of cable length in the laboratory, simulation beyond the range cannot be verified.

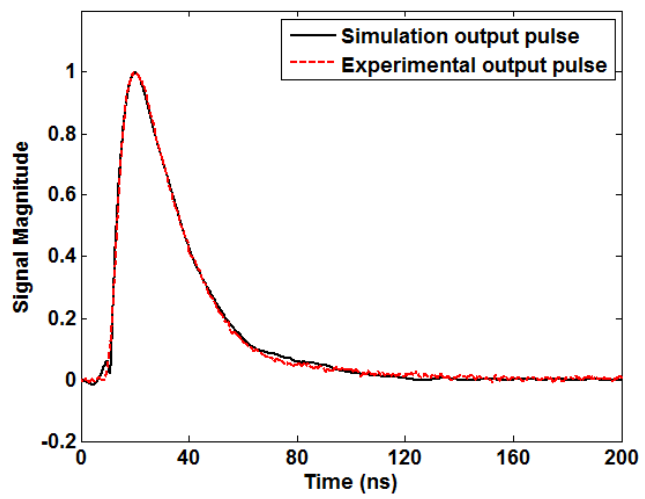

(a) Comparison of simulated and practical pulse - propagated $38.8 \mathrm{~m}$

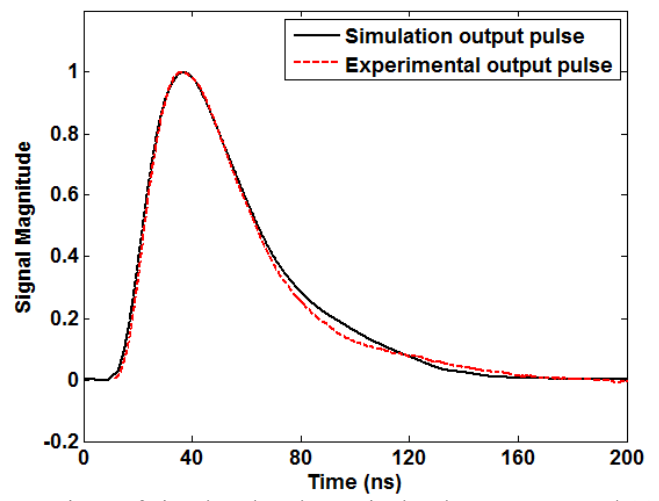

(b) Comparison of simulated and practical pulse - propagated $116.4 \mathrm{~m}$

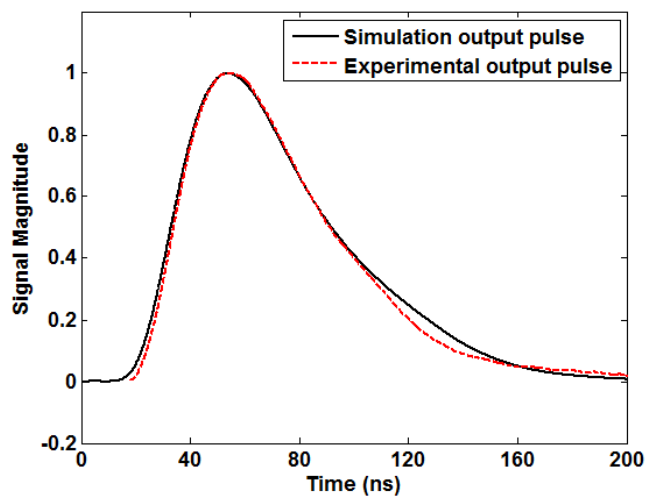

(c) Comparison of simulated and practical pulse - propagated $194 \mathrm{~m}$

Figure 13. Comparison between simulation and experimental results for pulse propagation in different cable lengths.

\subsection{PRACTICAL APPLICATION OF THE RTTF METHOD}

The RTTF method for on-line PD localization has been applied to an on-site measurement where the sampling rate was $125 \mathrm{MS} / \mathrm{s}$. PD activity was measured at both ends of an $11 \mathrm{kV}$ three-core Paper Insulated Lead Covered (PILC) underground distribution cable of about $1000 \mathrm{~m}$ in length. The test was carried out during service, so the voltage was at $11 \mathrm{kV}$. The cable is $1020 \mathrm{~m}$ in length with both ends earthed. The PD testing was carried out, with the HFCT attached at the earth strap, at one end of the cable first, and then at the other end one hour later. The time interval between the two measurements made in the study was of the order of about $1 \mathrm{~h}$ between consecutive data sets from on-line data gathering. After the online measurements, PD denoising and recognition techniques were applied to process the two sets of data to collect PD pulses. There are 178 and 193 PD pulses in the two sets of data respectively. Typical PD pulses from the measurements at both ends are demonstrated in Figure 14. Then filtering and interpolation techniques were used to extract rise time of all PD pulses. Statistical results of rise time of PD pulses in the two sets of data are given in Figure 15-16 and Table 1.

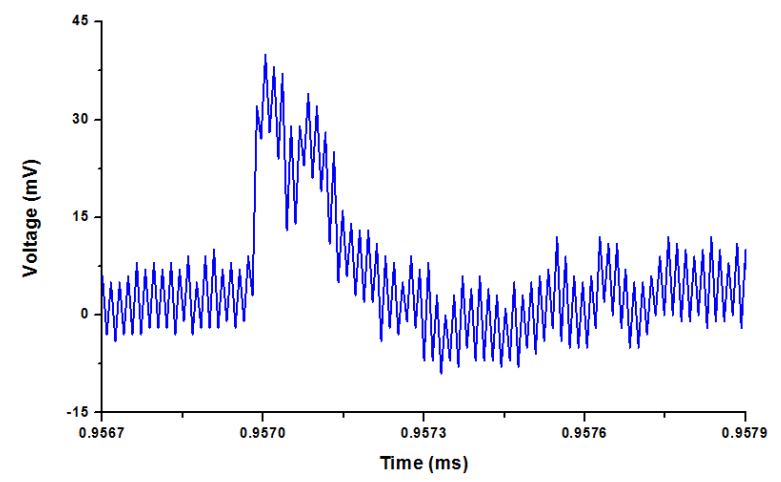

(a) A PD pulse detected at End A

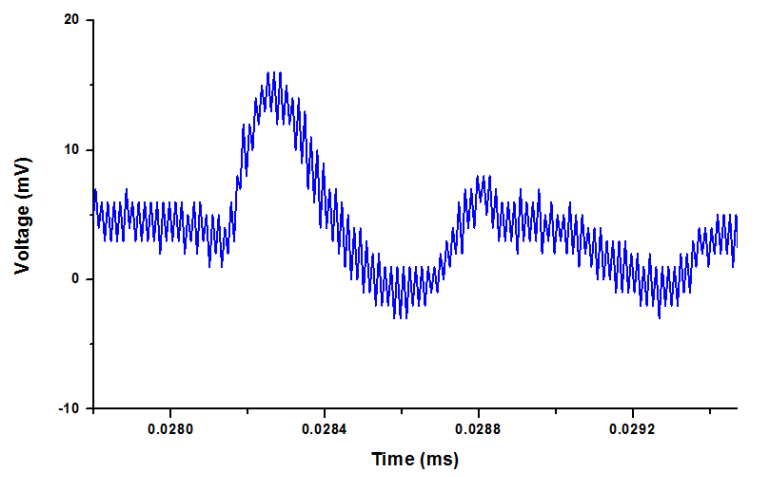

(b) A PD pulse detected at End B

Figure 14. Typical PD pulses from the measurements at two ends of $11 \mathrm{kV}$ PILC cable.

Figure 15 and 16 indicted that the relationship between $\mathrm{PD}$ rise time and number of PD pulses in both measurements is similar to a normal distribution, and the main rise time of PD pulses at the both ends concentrated at 20 ns and 71 ns separately.

As no sample of $11 \mathrm{kV}$ three-core PILC cable was available for experiments to obtain the RTTF, the RTTF for a single-core 11 $\mathrm{kV}$ EPR insulated cable is applied by the proposed method to 


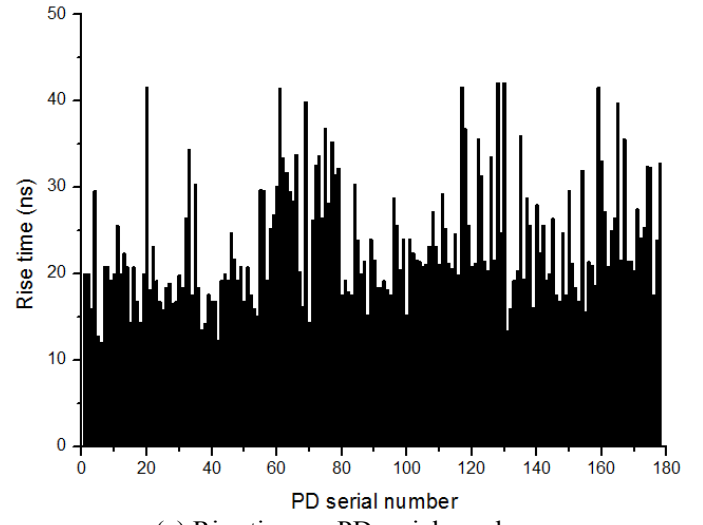

(a) Rise time vs PD serial number.

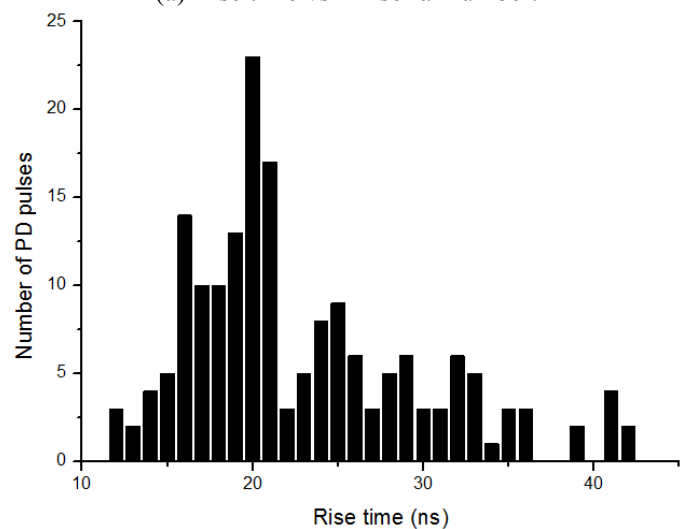

(b) Number of PD pulses vs Rise time

Figure 15. Result of rise time of $\mathrm{PD}$ pulses in the on-line data from end $\mathrm{A}$ of PILC cable

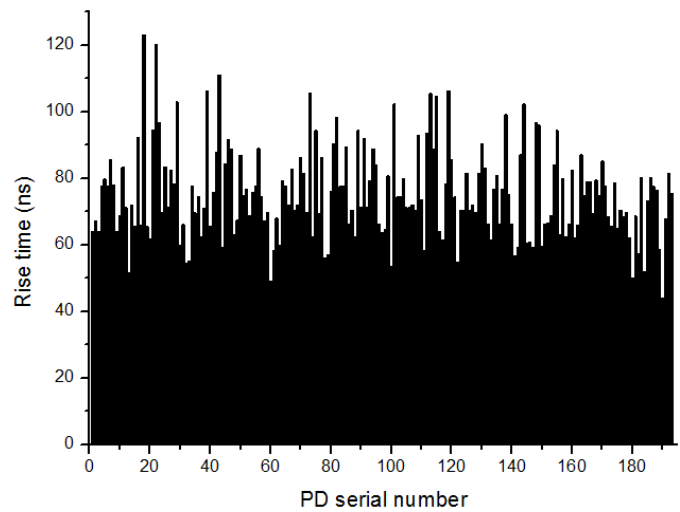

(a) Rise time vs PD serial number

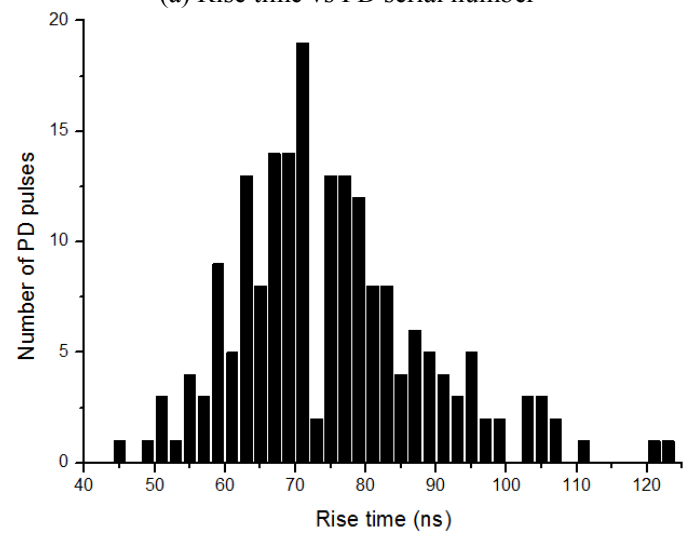

(b) Number of PD pulses vs Rise time

Figure 16. Result of rise time of PD pulses in the on-line data from end B of PILC cable.
Table 1. On-line data from two ends of a PILC cable.

\begin{tabular}{c|c|c}
\hline On-line data & $\begin{array}{c}\text { End A } \\
\text { (One end) }\end{array}$ & $\begin{array}{c}\text { End B } \\
\text { (The other end) }\end{array}$ \\
\hline Total number of PD pulses & 178 & 193 \\
Maximum probability of rise time & $20 \mathrm{~ns}$ & $71 \mathrm{~ns}$ \\
\hline
\end{tabular}

locate the PD source for the two on-line measurements separately. The location results shown in Figure 17 indicate the PD source is $239 \mathrm{~m}$ away from End A and $870 \mathrm{~m}$ away from End B.

In order to verify the results, the location of a fault was determined using off-line, cable mapping analysis, which indicated the actual source of PD is around $220 \mathrm{~m}$ away from one end (End A) while $800 \mathrm{~m}$ away from the other end (End B) [16].

From the comparison of the outcome of the fault location between the two methods, the RTTF technique for on-line PD localisation is confirmed correctly. The error in the RTTF method in this application will be discussed in Section 4.3.

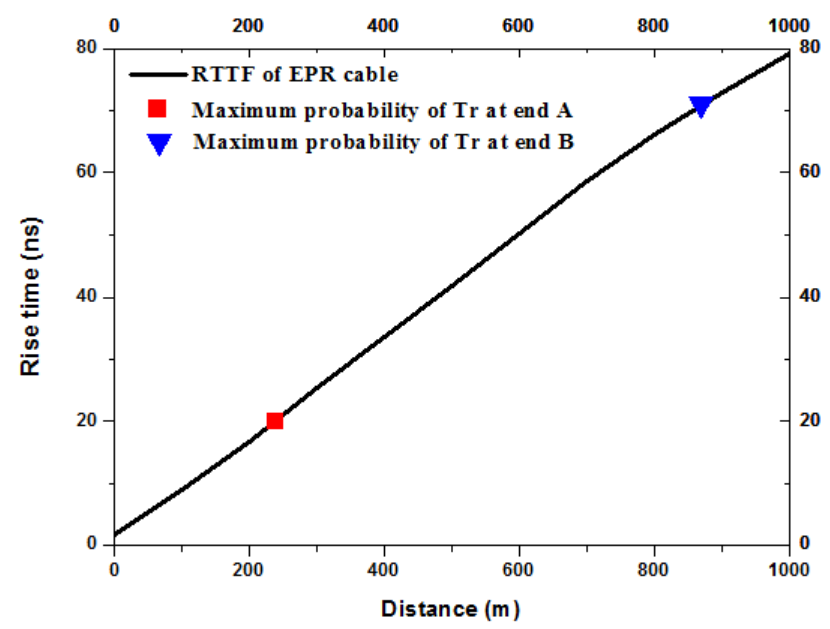

Figure 17. Results of RTTF method applied for a measurements at both ends of an $11 \mathrm{kV}$ PILC cable.

\subsection{DISCUSSIONS AND SOURCE OF ERROR}

For on-line PD measurements at each testing point in Section 4.2, the rise time of detected PD pulses from one fault source is not constant. The relationship between rise time and number of PD pulses is likely to be a normal distribution, as shown in Figures $15 \mathrm{~b}$ and $16 \mathrm{~b}$. This is because the sampling rate of 125 $\mathrm{MS} / \mathrm{s}$, vertical resolution of 8-bit under the noise affection can lead to an unsteady rise time of detected PD pulses. A sampling rate of $125 \mathrm{MS} / \mathrm{s}$ results in the time resolution of $8 \mathrm{~ns}$, which is not accurate enough for PD pulses with rise time of about $20 \mathrm{~ns}$ or $70 \mathrm{~ns}$. Vertical resolution of 8-bit can also affect the accuracy of rise time of detected $\mathrm{PD}$ pulses when the PD pulse amplitude is small within a strong noise environment. Therefore rise time of detected pulse is changeable.

Although the rise time of detected PD pulses from one source of fault is not constant, most of them have the same level rise time. Consequently, maximum probability of rise time in an online PD measurement should be used for RTTF method to locate the PD source.

The main error of the RTTF method in the on-line application in Section 4.2 results from the difference of RTTF between a single-core $11 \mathrm{kV}$ EPR insulated cable and three-core $11 \mathrm{kV}$ 
PILC cable. Sampling rate of $125 \mathrm{MS} / \mathrm{s}$, vertical resolution of 8bit and noise can lead to an error in rise time of the detected PD pulse as discussed above, which can also be a source of error in the RTTF technique for the On-line PD localisation monitoring system. In addition, due to heavy load carried in LV/MV cable systems, temperature could affect the resistive losses of the conductor, sheath and semi-conducting layers. Therefore, the attenuation of pulse propagation in cables differs from the laboratory conditions. This can lead to error in the cable transfer function, potentially another source of error in the RTTF method.

\section{CONCLUSION}

A novel method for on-line PD localization in cable systems, termed Rise-Time Transfer Function (RTTF) method, has been presented. This method is based on the change in rise time as a function of cable length along which a PD pulse has propagated. As on-line PD monitoring sensors installed at cable joints or terminations commonly comprise of a high frequency current transformer (HFCT) and a high-pass filter (HPF), detected PD pulse are attenuated and distorted by cable propagation, the HFCT used and the filter applied. Simulations of pulse propagation in a cable and PD monitoring system are performed based on analyses in the frequency domain using the concept of transfer functions. The simulation for pulse propagation in a cable has been verified by laboratory experiments and the RTTF technique for on-line PD localization has been applied in on-site measurements, which prove the RTTF method is a very valuable and useful PD localization technique.

In comparison with four other reported online PD localization methods, the RTTF method does not need to detect the reflected pulse while requiring only to detect the incident pulse at one measurement point, and can be used to localize a PD source which is further away from the PD detection point than other on-line methods.

Future work, based on the outcomes of this work, is to finish the knowledge base of RTTFs for all different types of cable used in power system to automatically localize sites of PD activity.

\section{ACKNOWLEDGEMENT}

The authors would like to thank EDF Energy for funding the work which yield the results presented here. The authors are also grateful to Xiao Hu, Professor Martin Judd, Dr Wah Hoon Siew and Professor Jianhui Yu for helping and sharing their expertise in PD monitoring and analysis.

\section{REFERENCES}

[1] R. Eriksson, R. Papazyan, and G. Mugala, "Localization of Insulation Degradation in Medium Voltage Distribution Cables", Industrial and Information Systems, First Int'1. Conf., pp. 167-172, 2006.

[2] D. Pommerenke, T. Strehl, R. Heinrich, W. Kalkner, F. Schmidt, and W.Weissenberg, "Discrimination between internal PD and other pulses using directional coupling sensors on HV cable systems", IEEE Trans. Dielect. Electr. Insul., Vol. 6, pp. 814-824, 1999.

[3] M.S. Mashikian, R. Bansal and R.B. Northrop, "Location and characterization of partial discharge sites in shielded power cables", IEEE Trans. Power Delivery, Vol. 5, pp. 833-839, 1990.

[4] R. Mardiana, and C.Q. Su, "Partial discharge location in power cables using a phase difference method", IEEE Trans. Dielect. Electr. Insul., Vol. 17, pp. 1738-1746, 2010.
[5] G. Katsuta, A. Toya, K. Muraoka, T. Endoh, Y. Sekii and C. Ikeda, "Development of a method of partial discharge detection in extrahigh voltage cross-linked polyethilene insulated cable lines", IEEE Trans. Power Delivery, Vol. 7, pp. 1068-1074, 1992.

[6] A. Cavallini, G.C. Montanari, and F. Puletti, "A novel method to locate PD in polymeric cable systems based on amplitude-frequency (AF) map", IEEE Trans. Dielect. Electr. Insul., Vol. 14, pp. 726-734, 2007.

[7] J. A. van Alste, and T. S. Schilder, "Removal of baseline wander and powerline interference from the ECG by an efficient FIR filter with a reduced number of taps", IEEE Trans. Biomed. Eng., Vol. 32, pp. 1052-1060, 1985.

[8] R. Papazyan, P. Pettersson, H. Edin, R. Eriksson, and U. Gafvert, "Extraction of high frequency power cable characteristics from S-parameter measurements", IEEE Trans. Dielect. Electr. Insul., Vol. 11, pp. 461-470, 2004.

[9] R. Papazyan, and R. Eriksson, "Calibration for time domain propagation constant measurements on power cables", , IEEE Trans. Instrumentation and Measurement, Vol. 52 , pp. 415-418, 2003.

[10] E.H.R. Gaxiola, and J.M. Wetzer, "Partial discharge modelling and measurements on micrometer voids in solid dielectrics", Dielectric Materials, Measurements and Applications, 7th Int'l. Conf., pp. 322-325, 1996.

[11] S. A. Boggs and G. C. Stone, "Fundamental limitations in the measurement of corona and partial discharge", IEEE Trans. Electr. Insul., Vol. EI-17, pp. 143$150,1982$.

[12] D. J. Smith, Fault Mode Analysis of High Voltage Bushings, Ph.D. thesis, Glasgow Caledonian University, UK, 2013.

[13] X. Song, C. Zhou, D.M. Hepburn, and M. Michel, "Second generation wavelet transform in PD measurement denoising", IEEE Trans. Dielectr. Electr. Insul., Vol. 14, pp. 1531-1537, 2007.

[14] W. Sweldens,"The lifting scheme: a custom-design construction of biorthogonal wavelets", Appl. Comput. Harmon. Anal., Vol. 3, pp. 186-200, 1996.

[15] X. Peng, C. Zhou, D.M. Hepburn, M.D. Judd, and W.H. Siew, “Application of K-means method to pattern recognition in on-line cable partial discharge monitoring”, IEEE Trans. Dielectr. Electr. Insul., Vol.20, pp. 754-761, 2013.

[16] C. Zhou, X. Song, M. Michel, and D.M. Hepburn, "On-line partial discharge monitoring in medium voltage underground cables", IET Sci., Measurement \& Technology, Vol. 3, pp. 354-363, 2009.

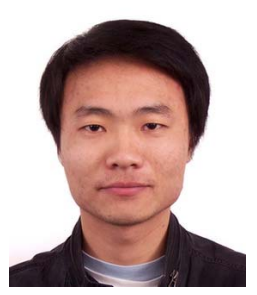

Bojie Sheng (M'13) was born in China. He received his B.Sc. degree from the School of Electrical Engineering, Wuhan University, China in 2008. He is now a Ph.D. candidate in the School of Engineering and the Built Environment, Glasgow Caledonian University, UK and his research is mainly focused on the diagnostic methodology for power cable insulation as well as lightning protection for microelectronic equipment.

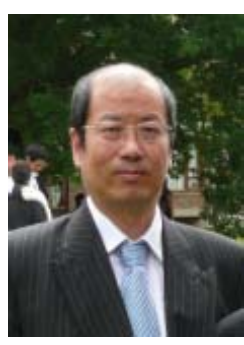

Chengke Zhou (M'06-SM'13) received the B.Sc. and M.Sc. degrees in electrical engineering from HuaZhong University of Science and Technology, China in 1983 and 1986, respectively, and the Ph.D. degree at the University of Manchester U.K., in 1994. Since then, he worked in Glasgow Caledonian University (GCU), as a Lecturer and Senior Lecturer, and in Heriot-Watt University as a Reader. In 2007 he returned to GCU as a Professor. He has published more than 100 papers in the area of PD based condition monitoring of $\mathrm{MV} / \mathrm{HV}$ plant and power system analysis. He is a Senior member of IEEE and Fellow of IET.

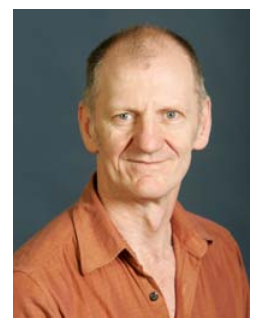

Donald M. Hepburn (M'08) received his B.A. (Hons) from the Open University in 1987and the Ph.D. degree from Glasgow Caledonian University (GCU) in 1994. He is a Senior Lecturer at GCU, a member of the Institute of Physics, the IET and C.Eng. He has 20 years of industrial research experience and has been involved in research into HV insulation systems at GCU for over 20 years. His research interests cover monitoring physical and chemical change in HV/MV insulation materials and application of advanced digital signal processing to information from electrical, acoustic and RF monitoring techniques. 


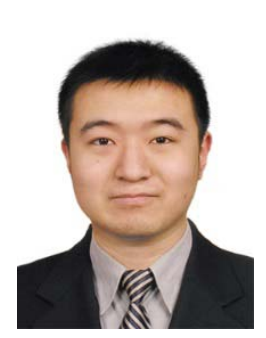

Xiang Dong was born in China. He received the B.Sc. degree from the North China Electrical Power University, China in 2011 and the Ph.D. degree in Glasgow Caledonian University in 2014. His research interests are circulating and leakage current in cable sheath and condition monitoring of power cables.

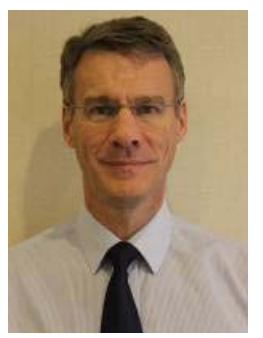

Graham Peers was born in Tel-Aviv, Israel in 1975. $\mathrm{He}$ received the B.Sc. degree from the Technion, Israel Institute of Technology, Haifa, Israel in 1995, the M.Sc. degree from the Massachusetts Institute of Technology, Cambridge, USA in 1999 and the Ph.D. degree from the University of the Negev, Beer Sheva, Israel in 2004 .

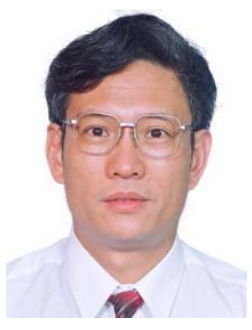

Wenjun Zhou (SM'13) was born in China on 1 July 1959. He received the Ph.D. degree in 1990 from Wuhan University of Hydraulic \& Electrical Engineering. Currently, he is a professor at the School of Electrical Engineering of Wuhan University, China. $\mathrm{He}$ is a member of the High Voltage Committee of the Chinese Society of Electrical Engineering (CSEE), the Electrotechnical Test and Measurement Committee of the China Electro-technical Society (CES), and the China Lightning Protection Standard Committee. He is also the vice director of the Hubei High Voltage Committee. His research interests include lightning protection and the diagnostic techniques for outdoor electrical insulations.

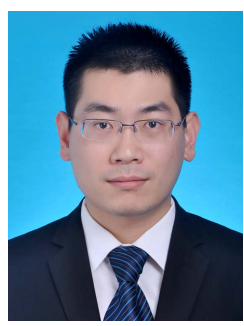

Zeyang Tang was born in Jingzhou, Hubei province, China, in 1987. He received the B.Sc. degree from the School of Electrical Engineering, Tianjin University, China in 2009. He is currently pursuing the Ph.D. degree in the School of Electrical Engineering, Wuhan University, China. His research is mainly focused on cable failure data analysis and cable asset management. 